\title{
The Potency of Formalism Logical Operations of Truth Tables Study
}

\author{
Radouane Kasour ${ }^{1}$, Naceur Achtaich ${ }^{2}$ Mohamed Bahra ${ }^{3}$, Brahim Nachit ${ }^{4}$, \\ Abdelwahed Namir ${ }^{5}$ and Mohammed Talbi, \\ 1,4,6 Observatory for Research in Pedagogy and Didactics University (ORPDU), University Hassan -II- \\ Mohammedia, Casablanca, Morocco. \\ ${ }^{1,2}$ Laboratory analysis, Modeling and Simulation ( LAMS), University Hassan -II-Mohammedia, Casablanca, \\ Morocco. \\ ${ }^{4,5}$ Laboratory of Information Technology and Modeling (LTIM), University Hassan -II- Mohammedia, \\ Casablanca, Morocco \\ ${ }^{2}$ Cell Observation and Research in Science Education and Technology (CORSET) - Regional Centre for Trades \\ Education and Training, Derb Ghalef, Casablanca, Morocco.
}

Abstract: In this article, we used the automata theory to highlight the syntactic property representing the formal knowledge, and also we can use other contexts to represent the semantic property.

Keywords - truth table, formalism, formal symbolic system, Artificial Intelligence, black box, automaton.

\section{INTRODUCTION}

The education system uses the active method to teach mathematics, based on activities at the beginning of each lesson to give meaning to mathematical concepts but normally presented by the knowledge of situations that do not always have the semantic property, and finally concludes by presenting the formal knowledge, then evaluates everything formal. So the education system considers that the student assimilates the semantic side, which may involve syntactic side he is given.

\section{Problem}

We consider the truth table of logical implication (equivalence, conjunction, disjunction); it represents one aspect of bivalent logic formalism.

Let us ask the question, in my opinion crucial follows: what is the epistemological significance of this table? In other words, what objects of knowledge can they be considered as if drifting derivable objects from this table? This study attempts to answer this question. Our goal is to show the role that the formalism sometimes occupies explicit, implicit in the evolution of scientific knowledge.

\section{III.1 The formalized language:}

\section{THEORETICAL FRAMEWORK}

1. We explicitly denote a finite or countable symbols, divided according to their use in constants, variables, logical symbols, symbols of relationships, symbols unfit (punctuation, for example, the use of which could be avoided by writing conventions).

A finite sequence of symbols is called an expression system.

2. Defining a subset of terms of the system, called well-formed expressions, or formulas system. Intuitively - but the reference to intuition is unrelated to the issue of the logician - these formulas are those which, in an interpretation of the system (for which it may have been built), have an intelligible meaning, representing either a statement of a relationship is namely a proposal (which can be true or false in logic "Binary", or more generally take a "truth value" determined. It's Wittgenstein who, by defining the "truth tables" of the propositional calculus, opened the possibility of axiomatically determine truth values.)

\section{III.1.1. symbolic system:}

We call a symbolic system a set of signs effectively given or effectively constructible.

\section{III.1.2. formal symbolic system:}

According to (GG GRANGER 2003) formal symbolic system is composed by three characters that are:

1. A formal system including rules.

2 - All of its signifiers can be reduced by decomposing a finite lexicon elementary signifiers. 
3 - The rules must be reduced to simple concatenation conditions of lexical elements, compliance conditions with which determines the "well-formed expressions" system.

\section{III.2. Formalism:}

"According to Klages, formalism, is the thought by pure signs". Computer programs are good examples. It is thought that such submission to the rule, the agreement is more important than thought by reference to reality.

"The purpose of formalist thinking, says Klages is: results of achieved thought without the effort of thinking, no found answers through research, the rule of the Spirit without the means established and the instrument of consciousness, which still depends to a part of life. Without doubt, the perfect formal would be a precision device without conscience, capable of a variety of worrying reactions which could then dial either in a workshop building or in a still,

We spontaneously associate the notion of formalism in philosophy and mathematics, rightly, for it is within these disciplines that the word takes its meaning clearer. The numbers meaning something (land, oil, railroads, workers, etc.), but they are themselves living a sovereign life, in the brains of wrestlers and non value significant: sign dominates the signified, and thinking by pure thoughts replace the meaningful units, and even thought by concepts. It is here that consist the essence of formalism. "

\section{IV.1. Research Methodology:}

\section{Practice Framework:}

We formulated a questionnaire which was distributed to thirty high school teachers. And presented "the implication truth table" as formal knowledge, and the proposed semantic side by specific examples "see questionnaire"

The result we found is, that 44\% responded "possible", 32\% responded "contingent", $20 \%$ responded "a necessary condition" and only $4 \%$ who say "impossible".

We can represent the results obtained by the graph above:

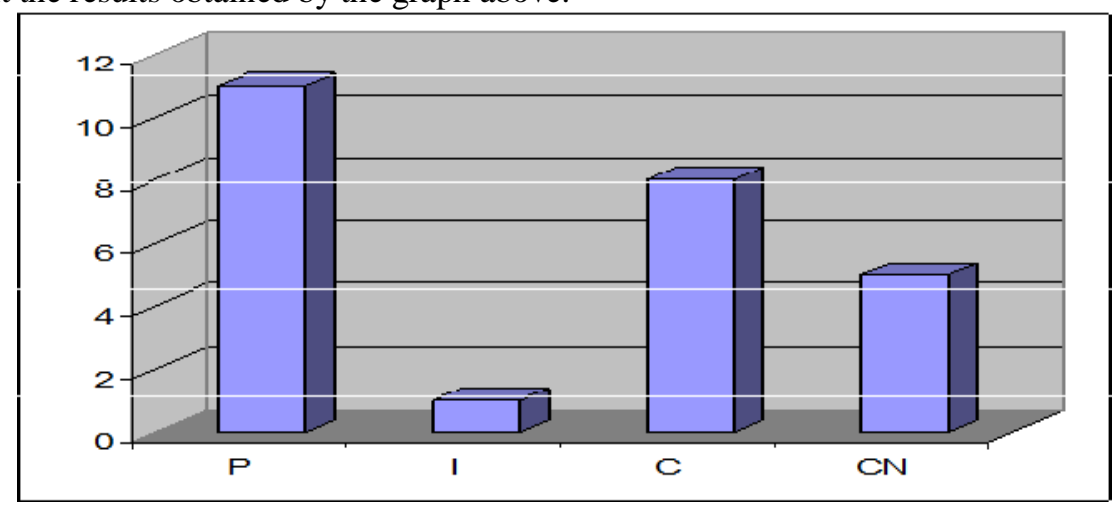

P: possible, I: impossible, : C: contingent

The conclusion is that the minority refuses to investigate how the proposed concept

« $\mathrm{P}=>\mathrm{Q} »$, this minority said "impossible" hence, the remainder is not opposed to the way of teaching this concept, and especially $44 \%$ say it's possible.

Hence, we can say that the semantic facilitates the intelligibility truth table of « $\mathrm{P}=>\mathrm{Q} »$.

\section{TRUTH TABLES STUDIES}

V.1. The implication truth table study:

The table looks like this:

\begin{tabular}{|l|l|l|}
\hline \multicolumn{1}{|c|}{$\mathbf{P}$} & $\mathbf{Q}$ & $p \Rightarrow q$ \\
\hline $\mathrm{T}$ & $\mathrm{T}$ & $\mathrm{T}$ \\
\hline $\mathrm{T}$ & $\mathrm{F}$ & $\mathrm{F}$ \\
\hline $\mathrm{F}$ & $\mathrm{T}$ & $\mathrm{T}$ \\
\hline $\mathrm{F}$ & $\mathrm{F}$ & $\mathrm{T}$ \\
\hline
\end{tabular}

Denote $\mathrm{P}$ and $\mathrm{q}$ two events which are observed as they occur, sometimes simultaneously, sometimes not. When can we say that the event $p$ implies $q$ event (we write then $p \Rightarrow q$ ) ? As a hypothesis search « $\mathrm{P}=>\mathrm{Q}$ » is an admissible/receivable hypothesis or inadmissible one under the following circumstances, 


\begin{tabular}{|l|l|l|l|}
\hline \multicolumn{1}{|c|}{$\mathrm{P}$} & $\mathrm{Q}$ & $\begin{array}{l}\text { Hypothesis : } \mathrm{p} \\
\Rightarrow \mathrm{q}\end{array}$ & $\begin{array}{l}\text { Hypothesis : } \\
\mathrm{N}(\mathrm{p} \Rightarrow \mathrm{q})\end{array}$ \\
\hline $\mathrm{O}$ & $\mathrm{O}$ & Receivable & Inadmissible \\
\hline $\mathrm{O}$ & $\mathrm{NO}$ & Inadmissible & Receivable \\
\hline
\end{tabular}

\begin{tabular}{|c|c|c|c|}
\hline NO & O & Receivable & Inadmissible \\
\hline NO & NO & Receivable & Inadmissible \\
\hline
\end{tabular}

In this admissibility table of the involvement hypothesis, we draw the following graph actions:

\begin{tabular}{|l|l|l|l|}
\hline \multicolumn{2}{|l|}{ Condition } & Actions & Actions \\
(On the observation of $\mathrm{p}$ and of $\mathrm{q})$ & $\begin{array}{l}\text { (On the assumption } \\
\mathrm{p} \Rightarrow \mathrm{q})\end{array}$ & $\begin{array}{l}\text { (On the assumption } \\
\mathrm{N} \ll \mathrm{p} \Rightarrow \mathrm{q})\end{array}$ \\
\hline $\mathrm{P}$ & $\mathrm{Q}$ & & \\
\hline $\mathrm{O}$ & $\mathrm{O}$ & Acceptance & Reject \\
\hline $\mathrm{O}$ & $\mathrm{NO}$ & Reject & Acceptance \\
\hline NO & $\mathrm{O}$ & Acceptance & Reject \\
\hline NO & NO & Acceptance & Reject \\
\hline
\end{tabular}

We may also consider the following action graph:

\begin{tabular}{|l|l|l|}
\hline $\begin{array}{c}\text { Designation of the } \\
\text { Module }\end{array}$ & Requirement & Permitted action \\
\hline$(\mathrm{OO})$ & $\mathrm{P}(\mathrm{O}) \& \mathrm{q}(\mathrm{O})$ & Hypothesize $\ll(\mathrm{p} \Rightarrow \mathrm{q}) »$ \\
\hline$(\mathrm{ON})$ & $\mathrm{P}(\mathrm{O}) \& \mathrm{q}(\mathrm{ON})$ & Hypothesize $\ll \mathrm{N}(\mathrm{p} \Rightarrow \mathrm{q}) »$ \\
\hline$(\mathrm{ON})$ & $\mathrm{P}(\mathrm{ON}) \& \mathrm{q}(\mathrm{O})$ & Hypothesize $\ll \mathrm{N}(\mathrm{p} \Rightarrow \mathrm{q}) »$ \\
\hline$(\mathrm{NN})$ & $\begin{array}{l}\mathrm{P}(\mathrm{NO}) \& \quad \mathrm{q} \\
(\mathrm{NO})\end{array}$ & Hypothesize $\ll(\mathrm{p} \Rightarrow \mathrm{q}) »$ \\
\hline
\end{tabular}

We can compare this gracte table notion or action graph, current research in logic: a gracte is a given set A of letters, $\varepsilon, \varphi, \gamma, \ldots .$. which are names of actions, a set $\mathrm{E}$ state denoted $\mathrm{x}, \mathrm{y}$, etc.. ; A set $\mathrm{P}$ of possible acts, ie types of symbols of $y \Rightarrow{ }_{\varepsilon} \mathrm{x}$ which we read: "if it's in the state $\mathrm{y}$, and if the action is $\varepsilon$, it goes into $\mathrm{x}$. "

In the context of current research in Artificial Intelligence, in writing $\mathrm{y} \Rightarrow_{\varepsilon} \mathrm{x}$, $\mathrm{y}$ can express a state of the blackboard, state satisfying a certain condition $\mathrm{c}$, in which an agent $\varepsilon$, for example, a student passes automatically to the table and performs a certain action, raising the status of the state $\mathrm{y}$ to the state $\mathrm{x}$. The pairs (C, A) which can be associated with symbol types $\mathrm{y} \Rightarrow_{\varepsilon} \mathrm{x}$ defining a gracte are told Modules, or Ks (acronym Knowledge source ) the blackboard is a model in the Model of the blackboard and the Modules are independent and do not communicate with each other.

Let PN (P unobserved) all PN $=\{(\mathrm{NO})(\mathrm{NN})\}$, formed the Modules $(\mathrm{NO})$ and $(\mathrm{NN})$, PN can be associated with the event "it is permissible to hypothesize the phenomenon that $\mathrm{p}$ implies the phenomenon q. "In the systems with knowledge bases (SBC) AI, PN, as Grouping Modules.

Giving rise to an event, says KSAR (an acronym for Knowledge Activation Report source), it is the same $\mathrm{OQ}(\mathrm{Q}$ observed) all $\mathrm{QO}=\{(\mathrm{OO})(\mathrm{NO})\}$, is associated with the same KSAR event that KSAR PN. The singleton $\mathrm{POQN}=\{\mathrm{ON}\}$ KSAR is associated with the event: "It is possible to advance the hypothesis that $\mathrm{p}$ does not cause q".

In another register, we can consider the truth table of logical implication as a black box that has the input data, among the elements of the set $\mathrm{E}$ as follows:

$\mathrm{E}=\{\{(\mathrm{p}, \mathrm{T}) ;(\mathrm{q}, \mathrm{T}) ;\{(\mathrm{p}, \mathrm{T}) ;(\mathrm{q}, \mathrm{F})\} ;\{(\mathrm{p}, \mathrm{F}) ;(\mathrm{q}, \mathrm{T})\} ;(\mathrm{p}, \mathrm{F}) ;(\mathrm{q}, \mathrm{F})\}$,

Matches output data among the elements of the set $\mathrm{S}$ as follows:

$$
\mathrm{S}=\{(\mathrm{p} \Rightarrow \mathrm{q}, \mathrm{T}) ;(\mathrm{p} \Rightarrow \mathrm{q}, \mathrm{F})\} ;
$$

The internal mechanism of this black box is unknown, we only know that it is a controller that, once an element $\mathrm{x}$ of $\mathrm{E}$ is given in the box as input, this controller takes series of state before displaying the corresponding element $\mathrm{y}$ of $\mathrm{S}$. Under these conditions, reveal the inner workings of the black box (with opaque walls) is to characterize this automaton as a machine having:

- A limited tape on the left, unrestricted on the right, bearing boxes will be registered or the input data, one letter per box, from the letters of an alphabet, ie: $L=\{p ; q ; T, F\}$; 
- A pickup ..;

- An alphabet $\mathrm{Q}=\{\mathrm{s} ; \mathrm{q} 0 ; \mathrm{q} 1, \ldots\}$ states in which each letter reflects the state in which the controller is at a given moment, we distinguish among these states an initial state $\mathrm{s}$ and acceptor states in case $\mathrm{Q}=\left\{\mathrm{s}, \pi, \pi, \pi^{\prime}, \pi^{\prime},(\mathrm{p} \Rightarrow \mathrm{q}, \mathrm{T}),(\mathrm{p} \Rightarrow \mathrm{q}, \mathrm{F})\right\}$

- Rules transition, reflecting how the controller switches from one state to another: these rules are of the form qi $1 \mathrm{k}$ qj that reads: "if the controller enters a state qi and s' he reads the letter lk, it goes to the state qi "an input is then accepted by the automaton if, at the end of cycle transitions caused by this input, the play-head an empty bed, an empty word B (white and is in one of its states acceptor, in this case, the acceptor states of our automaton are:

$\mathrm{Sp} \pi, \pi \mathrm{T} \pi, \pi \mathrm{q} \pi \mathrm{k}, \pi \mathrm{kT}(\mathrm{p} \Rightarrow \mathrm{q}, \mathrm{T}), \pi \mathrm{kF}(\mathrm{p} \Rightarrow \mathrm{q}, \mathrm{F}), \pi \mathrm{F} \pi^{\prime}, \pi^{\prime} \mathrm{q} \pi^{\prime} \mathrm{k}, \pi \mathrm{k}^{\prime} \mathrm{T}(\mathrm{p} \Rightarrow \mathrm{q}, \mathrm{T})$, and $\pi$ 'k $\mathrm{F}(\mathrm{p} \Rightarrow \mathrm{q}, \mathrm{T})$.

Note that an automaton of this kind is a theoretical model of the computer and a transition rule $\mathrm{qi}_{\mathrm{i}} \mathrm{l}_{\mathrm{k}} \mathrm{q}_{\mathrm{j}}$ can be manually written, reading as follows: "if $q_{i}$ is written below $\mathrm{q}_{j} \mathbf{l}_{\mathbf{k}}$ to its right then I examine below what letter is the letter that I have written to see if one of the transition rules is then applicable. "

\section{V.2. The conjunction truth table study:}

Consider the truth table for the conjunction.

It represents one of the aspects of the bivalent logic truth table formalism, the table is presented as follows:

\begin{tabular}{|l|l|l|}
\hline \multicolumn{1}{|c|}{$\mathrm{q}$} & $\mathrm{p}$ & $\mathrm{p} \wedge \mathrm{q}$ \\
\hline $\mathrm{T}$ & $\mathrm{T}$ & $\mathrm{T}$ \\
\hline $\mathrm{T}$ & $\mathrm{F}$ & $\mathrm{F}$ \\
\hline $\mathrm{F}$ & $\mathrm{T}$ & $\mathrm{F}$ \\
\hline $\mathrm{F}$ & $\mathrm{F}$ & $\mathrm{F}$ \\
\hline
\end{tabular}

Or $" \mathrm{p}^{\wedge} \mathrm{q}$ " is true only if $\mathrm{p}$ is true and $\mathrm{q}$ is true, while in other cases $" \mathrm{p} \wedge \mathrm{q}$ " is false.

Our goal is to give meaning and see the internal mechanism that takes place inside the truth table.

Denote by $\mathrm{p}$ and $\mathrm{q}$ two events is observed that they occur at the same time.

As the research hypothesis $" \mathrm{p}^{\wedge} \mathrm{q}$ " is an admissible hypothesis only if $\mathrm{p}$ and $\mathrm{q}$ are both observable at the same time, while in other cases the assumption $" \mathrm{p}^{\wedge} \mathrm{q}$ " is inadmissible.

So, we draw the following action graph:

\begin{tabular}{|c|c|c|c|}
\hline \multicolumn{2}{|c|}{ Conditions (on the observation of) $\mathrm{p}^{\wedge} \mathrm{q}$} & \multicolumn{2}{|c|}{$\begin{array}{l}\text { Actions relating to Actions relating } \\
\text { the hypo }\left(\mathrm{p}^{\wedge} \mathrm{q}\right)\end{array}$} \\
\hline $\mathrm{P}$ & Q & & \\
\hline $\mathrm{O}$ & $\mathrm{O}$ & ACCEPTANCE & REJECT \\
\hline $\mathrm{C}$ & NO & REJECT & ACCEPTANCE \\
\hline NO & $\mathrm{O}$ & REJECT & ACCEPTANCE \\
\hline $\mathrm{NO}$ & NO & REJECT & ACCEPTANCE \\
\hline
\end{tabular}

In another register, we can consider the table truth for " $\mathrm{p}^{\wedge} \mathrm{q}$ " as a black box which input data elements of the following set $\mathrm{E}$

$\mathrm{E}=\{\{(\mathrm{p}, \mathrm{T}) ;(\mathrm{q}, \mathrm{T})\} ;\{(\mathrm{p}, \mathrm{T}) ;(\mathrm{q}, \mathrm{F})\} ;\{(\mathrm{p}, \mathrm{F}) ;(\mathrm{q}, \mathrm{T})\} ;(\mathrm{p}, \mathrm{F}) ;(\mathrm{q}, \mathrm{F})\}$

Corresponding the data output from the among elements of the following set $\mathrm{S}$

$\mathrm{S}=\left\{\left(\mathrm{p}^{\wedge} \mathrm{q}, \mathrm{T}\right) ;\left(\mathrm{p}^{\wedge} \mathrm{q}, \mathrm{F}\right)\right\}$

The internal mechanism of this black box is unknown, we only know that it is a controller that once an element $\mathrm{x}$ of $\mathrm{E}$ is given in the box as input, this is a series automaton states before displaying the element $\mathrm{y}$ of $\mathrm{S}$, corresponding to these conditions reveal the inner workings of the black box is to characterize the automaton in the automaton " $\mathrm{p}^{\wedge} \mathrm{q}$ "

The acceptor states of our automaton are (p, q, T), (p, q, F) and we propose the following rules for our automaton transitions are:

$\operatorname{Sp} \pi \pi \mathrm{T} \pi, \pi \mathrm{q} \pi \mathrm{k} \pi \mathrm{kT}\left(\mathrm{p}^{\wedge} \mathrm{q}, \mathrm{T}\right), \pi \mathrm{k} F\left(\mathrm{p}^{\wedge} \mathrm{q}, \mathrm{F}\right), \pi \mathrm{F} \pi, \pi^{\prime} \mathrm{q} \pi \mathrm{\prime}^{\prime} \mathrm{k} \pi^{\prime} \mathrm{k} \mathrm{T}\left(\mathrm{p}^{\wedge} \mathrm{q}, \mathrm{F}\right), \pi^{\prime} \mathrm{k} F\left(\mathrm{p}^{\wedge} \mathrm{q}, \mathrm{F}\right)$

Automaton checking

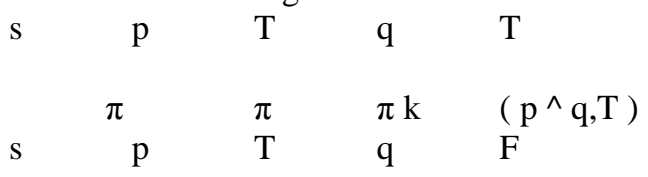




$\begin{array}{ccccc} & \pi & \pi & \pi \mathrm{k} & \left(\mathrm{p}^{\wedge} \mathrm{q}, \mathrm{F}\right) \\ \mathrm{s} & \mathrm{p} & \mathrm{F} & \mathrm{q} & \mathrm{T} \\ & \pi & \pi^{\prime} & \pi^{\prime} \mathrm{k} & \left(\mathrm{p}^{\wedge} \mathrm{q}, \mathrm{F}\right) \\ & \mathrm{s} & \mathrm{F} & \mathrm{q} & \mathrm{F} \\ & & & & \\ & \pi & \pi^{\prime} & \pi{ }^{\prime} \mathrm{k} \quad\left(\mathrm{p}^{\wedge} \mathrm{q}, \mathrm{F}\right)\end{array}$

Where was given although the controller is verified.

\section{V.3. The disjunction truth table study:}

The same way we will consider the truth table of disjunction "p v q"

\begin{tabular}{|l|l|l|}
\hline$p$ & $q$ & $p \vee q$ \\
\hline$T$ & $T$ & $T$ \\
\hline$T$ & $F$ & $T$ \\
\hline$F$ & $T$ & $T$ \\
\hline$F$ & $F$ & $F$ \\
\hline
\end{tabular}

It also represents an aspect of the formalization of bivalent logic.

We have then, "p v q" is false only in the case where p is false and q is false, otherwise it's true.

So, we denote by $p$ and q two events which are observed as they occur at the same time.

As the research hypothesis "p v q" is inadmissible only if $\mathrm{p}$ and $\mathrm{q}$ is inadmissible at the same time as the assumption "p v q" is admissible for other cases.

So we can draw the graph of action:

\begin{tabular}{|c|c|c|c|}
\hline \multicolumn{2}{|c|}{$\begin{array}{l}\text { Condition (on the observation } \\
\text { of } p \mathrm{vq} \text { ) }\end{array}$} & \multirow[t]{2}{*}{$\begin{array}{l}\text { Actions relating to } \\
\text { the hypo }(\mathrm{p} \vee \mathrm{q})\end{array}$} & \multirow[t]{2}{*}{$\begin{array}{l}\text { Actions relating to } \\
\text { the hypo } \mathrm{N}(\mathrm{p} \vee \mathrm{q})\end{array}$} \\
\hline $\mathrm{P}$ & $\mathrm{q}$ & & \\
\hline $\mathrm{O}$ & $\mathrm{O}$ & Acceptance & Reject \\
\hline $\mathrm{O}$ & No & Acceptance & Reject \\
\hline No & $\mathrm{O}$ & Acceptance & Reject \\
\hline No & No & Reject & Acceptance \\
\hline
\end{tabular}

In another register can be considered the truth table of "p v q 'as a black box which has input data among the elements of the set that matches the outputs of elements among all elements of the set

$$
S=\{(p \vee q, T) ;(p \vee q, F)\}
$$

Just as we did for "p^ $\mathrm{q}$ " we will propose the following rules for our automaton transitions that are

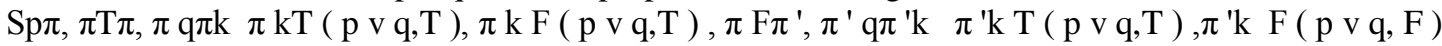
Automaton checking

$\begin{array}{lcccc}\mathrm{s} & \mathrm{p} & \mathrm{T} & \mathrm{q} & \mathrm{T} \\ & \pi & \pi & \pi \mathrm{k} & (\mathrm{p} \mathrm{v} \mathrm{q}, \mathrm{T}) \\ \mathrm{s} & \mathrm{p} & \mathrm{T} & \mathrm{q} & \mathrm{F} \\ & \pi & \pi & \pi \mathrm{k} & (\mathrm{p} \mathrm{v} \mathrm{q,T}) \\ \mathrm{s} & \mathrm{p} & \mathrm{F} & \mathrm{q} & \mathrm{T} \\ & \pi & \pi^{\prime} & \pi^{\prime} \mathrm{k} & (\mathrm{p} \mathrm{v}, \mathrm{T}) \\ \mathrm{s} & \mathrm{p} & \mathrm{F} & \mathrm{q} & \mathrm{F} \\ & \pi & \pi^{\prime} & \pi^{\prime} \mathrm{k} & (\mathrm{p} \vee \mathrm{q}, \mathrm{F})\end{array}$

Hence, the given automaton is checked.

\section{V.4. The equivalence truth table study:}

We will consider the truth table of equivalence "p $\Leftrightarrow \mathrm{q} "$ at the same way 


\begin{tabular}{|l|l|l|}
\hline $\mathrm{q}$ & $\mathrm{p}$ & $\mathrm{p} \Leftrightarrow \mathrm{q}$ \\
\hline $\mathrm{T}$ & $\mathrm{T}$ & $\mathrm{T}$ \\
\hline $\mathrm{T}$ & $\mathrm{F}$ & $\mathrm{F}$ \\
\hline $\mathrm{F}$ & $\mathrm{T}$ & $\mathrm{F}$ \\
\hline $\mathrm{F}$ & $\mathrm{F}$ & $\mathrm{T}$ \\
\hline
\end{tabular}

It also represents aspects of bivalent logic formalism

We have, then "p $\Leftrightarrow q$ " is true if $p$ and $q$ represent the same truth, otherwise it's false

So if we denote by $\mathrm{p}$ and $\mathrm{q}$ two events that we observe, they occur at the same time.

As the research hypothesis " $\mathrm{p} \Leftrightarrow \mathrm{q}$ " is admissible if $\mathrm{p}$ and $\mathrm{q}$ are admissible or inadmissible at the same time.

So we can draw the graph of action:

\begin{tabular}{|l|l|l|l|}
\hline \multicolumn{2}{|l|}{ Condition (on the observation of $\mathrm{p} \Leftrightarrow \mathrm{q})$} & $\begin{array}{l}\text { Action relating } \\
\text { to the hypo } \mathrm{p} \Leftrightarrow \mathrm{q}\end{array}$ & $\begin{array}{l}\text { Action relating } \\
\text { to the hypo } \mathrm{N}(\mathrm{p} \Leftrightarrow \mathrm{q})\end{array}$ \\
\hline $\mathrm{P}$ & $\mathrm{q}$ & & \\
\hline $\mathrm{O}$ & $\mathrm{O}$ & Acceptance & Reject \\
\hline O & No & Reject & Acceptance \\
\hline No & O & Reject & Acceptance \\
\hline No & No & Acceptance & Reject \\
\hline
\end{tabular}

In another register can be considered the truth table of "p $\Leftrightarrow q "$ as a black box which has input data from the output elements among the elements of the set.

$$
\mathrm{S}=\{(\mathrm{p} \Leftrightarrow \mathrm{q}, \mathrm{T}) ;(\mathrm{p} \Leftrightarrow \mathrm{q}, \mathrm{F})\}
$$

Just as we did for "p^ $\mathrm{q}$ " and "p v q", we will propose the following rules for our automaton transitions that are $\mathrm{Sp} \pi ; \pi \mathrm{T} \pi ; \pi \mathrm{q} \pi \mathrm{k} ; \pi \mathrm{kT}(\mathrm{p} \Leftrightarrow \mathrm{q}, \mathrm{T}), \pi \mathrm{kF}(\mathrm{p} \Leftrightarrow \mathrm{q}, \mathrm{F}), \pi \mathrm{F} \pi^{\prime}, \pi^{\prime} \mathrm{q} \pi^{\prime} \mathrm{k}, \pi^{\prime} \mathrm{k} \mathrm{T}(\mathrm{p} \Leftrightarrow \mathrm{q}, \mathrm{F})$, $\pi$ 'k F ( $\mathrm{p} \Leftrightarrow \mathrm{q}, \mathrm{T})$,

\begin{tabular}{lcccl}
\multicolumn{5}{c}{ Automaton checking } \\
$\mathrm{s}$ & $\mathrm{p}$ & $\mathrm{T}$ & $\mathrm{q}$ & $\mathrm{T}$ \\
& $\pi$ & $\pi$ & $\pi \mathrm{k}$ & $(\mathrm{p} \Leftrightarrow \mathrm{q}, \mathrm{T})$ \\
$\mathrm{s}$ & $\mathrm{p}$ & $\mathrm{T}$ & $\mathrm{q}$ & $\mathrm{F}$ \\
& $\pi$ & $\pi$ & $\pi \mathrm{k}$ & $(\mathrm{p} \Leftrightarrow \mathrm{q}, \mathrm{F})$ \\
$\mathrm{s}$ & $\mathrm{p}$ & $\mathrm{F}$ & $\mathrm{q}$ & $\mathrm{T}$ \\
& $\pi$ & $\pi^{\prime}$ & $\pi \mathrm{k}$ & $(\mathrm{p} \Leftrightarrow \mathrm{q}, \mathrm{F})$ \\
$\mathrm{s}$ & $\mathrm{p}$ & $\mathrm{F}$ & $\mathrm{q}$ & $\mathrm{F}$ \\
& $\pi$ & $\pi^{\prime}$ & $\pi \mathrm{k}$ & $(\mathrm{p} \Leftrightarrow \mathrm{q}, \mathrm{T})$
\end{tabular}

Hence, the given automaton is checked.

\section{CONCLUSIONS}

The question arises: what is the point of these automaton for the student? And what is it?

To answer these questions, we must first make an assessment of the lessons given to students of logic, and see is that the student understands the usefulness of the truth table or not?

Sure there are students who apply the truth table adequately but do not know which operation occurs inside the table, so we have a risk that student forgets the application by the end of the lesson in logic.

That's why we have the benefit of giving the student the internal mechanism of a truth table and especially the first time it is presented to him.

\section{REFERENCES}

[1] Gilles-Gaston Granger, “ Philosophie, Langage, Science“ les Ulis Cedex A, France, EDP Sciences. 2003

[2] Desanti, Jean-Toussaint, La Philosophie silencieuse ou Critique des philosophies de science, Paris, Éditions du Seuil,. 1975

[3] Ludwig,, Les principes de la caractérologie, Paris, Delachaux et Niestlé, 1950

[4] Jean-Luis Dessailles, Aux origines du langage : une histoire naturelle de la parole, Paris, HEMES Science Publicatio2000

[5] http://agora.qc.ca/mot.nsf/Dossiers/Formalisme

[6] http://fr.wikipedia.org/wiki/Grammaire_formelle\#Langages

[7] http://fr.wikipedia.org/wiki/Connaissance

[8] http://fr.wikipedia.org/wiki/Gestion_des_connaissances\#Connaissances_tacites_vs_connaissa nces_explicites

[9] http://www.universalis.fr/encyclopedie/formalisme/1-1-idee-de-connaissance-formelle/ Authors Article: Etienne Balibar (masterassistant at the University of Paris-I), Pierre MACHEREY (maitre-assistant at the University of Paris-I) 